\title{
REFLEXIONES SOBRE LA ECONOMÍA COLABORATIVA Y EL CAPITALISMO DE LAS EMOCIONES: NUEVOS RETOS EN EL ANÁLISIS DEL CONFLICTO CAPITAL-VIDA
}

\author{
Some reflexions about the Collaborative Economy and the Emotions \\ Capitalism: new challenges in the analysis \\ of the conflict between Capital and Life
}

Irati Mogollón García*

Universidad del País Vasco / Euskal Herriko Unibertsitatea

\begin{abstract}
RESUMEN
La irrupción de las nuevas (y no tan nuevas) tecnologías de la comunicación (Castells, 2006) con los dispositivos estratégicos de los Smart phones e Internet, están transformando profundamente nuestros esquemas sociales, nuestras relaciones y los modelos de producción. Transformaciones que han convergiendo y suscitado la diversa gama de empleos y servicios conocidos bajo el paraguas de la «Economía Colaborativa», detonando el camino hacia la digitalización de las relaciones laborales, con su esperable traducción en la digitalización de las condiciones laborales. El presente texto nace bajo el objetivo de una revisión feminista de estas transformaciones, insinuando interrelación entre la Economía Colaborativa y la noción de Capitalismo de las Emociones propuesta por Arlie Hochschild (1995). Se pretende aportar en la reflexión colectiva sobre los retos generados en la coyuntura actual de conflicto entre el Capital y la Vida (Orozco, 2006) y debatir sobre qué es lo que sucede cuando las emociones, el ejercicio de colaborar y las experiencias pasan a ser parte esencial del producto y del proceso de producción de capitales.

Palabras clave: sostenibilidad de la vida, capitalismo de las emociones, economía colaborativa.

\section{ABSTRACT}

The irruption of new (and not so new) technologies of communication (Castells, 2006) with Smart phones and Internet strategic devices are deeply transforming our social schemes, our relationships, and production models. These transformations have converged and raised the diverse range of jobs and services known under the umbrella of "Collaborative Economy". Consequently, it has detonated the path towards the digitalisation of the labour relationships, with its expected translation in the digitalisation of the laboral conditions. The present text comes into scene with the goal of a feminist revision of these transformations, insinuating interrelation between the Collaborative Economy and the notion of Emotions Capitalism proposed by Arlie Hochschild (1995). The authors have two main goals. Firstly, to provide a reflection on the challenges generated in the current situation of conflict between Capital and Life (Orozco, 2006). And secondly, to debate on what is happening with emotions, the exercise of collaboration and experiences that become essential part of the product and process of capitals production.
\end{abstract}

Keywords: sustainability of life, emotions capitalism, collaborative economy

* Correspondencia a: Irati Mogollón García. Facultad de Ciencias Sociales y de la Comunicación, Campus UPV/EHU. Barrio Sarriena s/n. 48940-Leioa, Bizkaia - irati.mogollon@ehu.eus -

Cómo citar: Mogollón García, Irati. (2019). «Reflexiones sobre la economía colaborativa y el capitalismo de las emociones: nuevos retos en el análisis del conflicto Capital-Vida»; Lan Harremanak, 41, 141-164. (https://doi.org/10.1387/lan-harremanak.20928)

Recibido: 12 junio, 2019; aceptado: 25 junio, 2019.

ISSN 1575-7048 - eISSN 2444-5819 / (C) 2019 UPV/EHU 


\section{SUMARIO}

1.Introducción.-2. Nuevos cercamientos en el conflicto Capital-Vida.-3. El diálogo entre la economía colaborativa y las emociones.-4. Un último aliciente: El pensamiento positivo.-5. Algunas conclusiones.-6. Bibliografía.

\section{Introducción}

Si torcemos la vista atrás, viendo los cambios que en la última década hemos vivido, centrados en las sociedades occidentales conocidas como el norte global, el vértigo que podríamos sentir al principio del estómago resulta, cuanto menos, considerable. Quizás, al igual que nuestros mayores con su distintiva frase de "antes todo esto era campo", nosotras y nosotros también podríamos memorar aquellos años en los que nuestro mundo se desarrollaba sin internet y sin los Smartphone. Las diferencias entre el abismo de los cambios que vivieron nuestras generaciones pasadas frente a la nuestra, sin embargo, pudieran residir en un factor concreto: la intensa velocidad de los acontecimientos.

Si echamos unas breves cuentas, podemos apreciar que los móviles con pantallas táctiles llegaron a popularizarse en el 2011, aplicaciones como WhatsApp o Facebook llegaron en el 2009 y 2004 respectivamente y portales de video como YouTube, por su parte, en 2005. Si bien internet ya suma 40 ańos de edad con su creación en 1972, lo verdaderamente impactante es cómo estas tecnologías o dispositivos han transformado las formas de relacionarnos, los procesos de producción, los modelos de empleo y las formas de sostener la vida que teníamos en cuestión de años. La velocidad de los acontecimientos es tal, que hoy día nos vemos en la necesidad de relatar los sucesos en años y no en décadas. Éstas transformaciones, junto con el estallido de la crisis global o lo que algunas denominan como reestructuración capitalista global (Albarracín, 2010) a mediados del 2007/8 nos lleva a preguntarnos sobre cuáles son los retos de sostenibilidad de la vida a los que nos enfrentamos en el presente o futuro más inmediato.

Si bien las siguientes líneas son escasas para relatar los múltiples procesos que toman parte en este archipiélago de realidades, a continuación, apostamos por introducir ciertos debates en la arena del análisis y coloquio social actual desde un enfoque de sostenibilidad de la vida en el centro. Para ello, se parte de un breve repaso teórico a los conceptos de sostenibilidad de la vida, conflicto Capital-Vida y la acumulación capitalista dentro de lo que se han 
denominado como nuevos cercamientos en el conflicto Capital-Vida. Después, se abre el diálogo entre la economía colaborativa y las emociones, situando ciertos matices de las relaciones entre esos dos elementos y observando cómo se transforman las relaciones laborales desde esas prácticas emocionales. Más adelante, se introduce un último aliciente en la ecuación elaborada, el del pensamiento positivo como piedra angular para esta narrativa del alegato hacia lo colaborativo y lo emotivo de la escena social. En este último apartado se evidencia que no cualquier emoción vale en la nueva fórmula de la(s) Economía(s) Colaborativa $(s)^{1}$ y los conflictos que ésta suscita. Finalmente, a modo de cierre presentaremos unas brevísimas conclusiones y reflexiones al aire para seguir alimentando y aportando en los debates colectivos actuales.

\section{Nuevos cercamientos en el conflicto Capital-Vida}

El enfoque desde el que se pretende trabajar nace gracias a las innumerables propuestas que feministas y ecofeministas llevaron a cabo (Carrasco, 2001; Orozco, 2006; Herrero, 2013; Federici, 2018) en una convergencia teórica surgida desde los movimientos sociales y las afluencias académicas (Carrasco, Borderías, Torns, 2011). Ésta mirada parte de la crítica a favor de descentralizar la referencia del marco de trabajo asalariado (Himmelweit, 1995) y el proceso de producción de mercancías como único indicador de bienestar social y riqueza. Se reivindica que en el centro del análisis socioeconómico se deben situar las necesidades sociales y bienestares producidos, tanto como marco de análisis, como a modo de objetivo (Benería, 1999; Picchio, 1999; Carrasco, Borderías, Torns, 2011; Orozco, 2006).

Por ello, se apuesta no solamente por el uso de la noción de cuidados (Thomas, 1993; Carrasco, 1991; Hochschild, 1995; Daly y Lewis, 2000; Benería, 2008; Carrasquer, 2013) sino también por visibilizar el proceso de sostenibilidad de la vida y el conflicto existente entre el Capital y la Vida a la hora de sostenerla. Puesto que, como señala Amaia Pérez Orozco (2012) es «el propio proyecto modernizador, la idea misma de desarrollo, progreso y crecimiento» (Orozco, 2012) lo que está hoy en día en crisis con su precariedad y vulnerabilidad (Carrasco, 2017; Picchio, 2009; Orozco 2014; Herrero, 2013) junto con la aparición de los nuevos riesgos sociales (Taylor-Gooby, 2004) y la profunda crisis de los cuidados (Izquierdo, 2003; Picchio, 2009; Dalla Costa, 2009; Carrasquer, 2013).

\footnotetext{
${ }^{1}$ El término de Economía Colaborativa es una noción de reciente producción ciertamente abstracta, pero con características específicas a su vez. Por ello, aun sabiendo que no hay una sola Economía Colaborativa, que no existe una definición monolítica respecto a la misma, utilizaremos en pos de la fluidez narrativa el singular de este término que se entiende abstracto y ciertamente plural, pero que comparte una amplia amalgama de características las cuales nos permiten hablar en parámetros individuales.
} 
En esta noción de conflicto entre el Capital y la Vida se amplía el concepto de Vida, también haciendo referencia a la naturaleza, más allá de la vida humana. Entre sus teóricas ecofeministas conocidas encontramos a Vandana Shiva, Maria Mies, Ariel Salleh o Yayo Herrero, que subrayan las similitudes entre el trato existente con la naturaleza y el trato que se tiene con las mujeres. Dicho paralelismo no se constituirá desde los discursos de la esencia femenina y su relación con la naturaleza, por el contrario, en sus trabajos subrayan que a ambas se las constituye como recursos. Recursos que son extraídos y utilizados por y para el hombre en los ciclos de producción capitalistas, pero sin ninguna clase de agencia ni reconocimiento de valor propio. Esta omisión de la capacidad productiva y creativa de la naturaleza y de las mujeres, será la clave de su expolio.

Por ello, desde el ecofeminismo se denunció el modelo de economía y desarrollo actual, pues en ellos quedan completamente excluidos el debate de la vida humana y los límites ecológicos de este planeta que las doctrinas liberales se niegan a reconocer. Señalan, junto con las economistas feministas, que el ecofeminismo «trastoca las bases fundamentales del paradigma económico capitalista y desvela que su lógica es incompatible con la de un mundo sostenible y justo» (Herrero, 2016: 8).

Para finalizar, otra arista más del conflicto Capital-Vida que quisiéramos visibilizar a la hora de plantear esta reflexión colectiva sobre las Economías Colaborativas y el papel de las emociones en la coyuntura actual es el de los nuevos cercamientos de los comunes (Ostrom, 1990) o los nuevos modelos de acumulación primitva u originaria (Federici, 2010; Hartsock, 2011).

Karl Marx (1867), en el primer volumen de su famosa obra de El Capital, nos planteó el término de acumulación originaria o acumulación primitiva, para explicar cómo se generaron las condiciones previas en la creación del capitalismo actual. En este sentido, hacía referencia al ejercicio de privatización de los medios de producción desarrollado entre los siglos XIV y XVI. Este ejercicio de privatización y expropiación, desembocó en lo que serían futuros trabajadores y trabajadoras sin medios. Afectó sobre todo a las grandes masas rurales, destruyendo de forma violenta y abusiva las formas tradicionales de derechos de acceso de la población a los medios de producción y recursos naturales como son los derechos comunales, el expolio de América, la vinculación de los siervos a la tierra, etc.

Con su obra y posteriores aportaciones teóricas, al hilo de la acumulación originaria (Harvey, 2003; Federicci, 2018), se evidenció que la riqueza de las naciones europeas y estadounidenses no podía comprenderse sin el expolio y la violencia ejercida hacia los territorios africanos, asiáticos y latinoamericanos. Son los siglos de esclavismo, genocidios y expolios de los regímenes coloniales, los que marcan los hitos en los que se fundamenta la riqueza de las naciones y el modelo de desarrollo capitalista actual. 
En 2003, David Harvey planteó la teoría de una nueva fase de esa acumulación marxista conocida como acumulación por desposesión. Haciendo referencia sobre todo a una fase de sobreacumulación del capital, subraya la mercantilización de ámbitos hasta entonces cerrados al mercado. Nos relata cómo en occidente, con el método de acumulación originaria y bajo el objetivo de mantener el capitalismo actual, se han ido sistemáticamente aplicando ejercicios de acumulación por desposesión como las privatizaciones de empresas públicas, las trampas de la deuda, la redistribución de la renta y las especulaciones financieras generadas a partir de las multitudinarias crisis desde 1970 hasta la más actual del 2008.

Estas teorías sirven para comprender las bases sobre las cuales se escribe y reescribe el capitalismo en sus multitudinarias fases y su conflicto permanente con la vida. A esta idea de rapiña capitalista de las esferas de la vida, se le da una vuelta de tuerca de la mano de multitud de feministas (Federici, 2010; Hartsock, 2011; Ezquerra, 2012), al construir una correlación entre los conceptos de acumulación originaria y acumulación por desposesión, con el papel de las mujeres no asalariadas y el papel de producción/reproducción de capitales en el espacio doméstico. De este modo, Silvia Federici (2010), en su reconocido libro «El Calibán y la Bruja. Mujeres, cuerpo y acumulación originaria», hace visible lo que se denomina como un nuevo campo de acumulación y de batalla: los cuerpos de las mujeres. Con esta idea, se plantea no solamente el expolio de los medios de producción materiales, sino también el expolio de los medios de reproducción materiales (cocinar, limpiar...) e inmateriales (afectos, atenciones, cuidados, educación...) del ámbito de lo privado y lo femenino.

Dándole una última revisión crítica al concepto, Nancy Hartsock (2011), en "A New Moment of Primitive Accumulation", apunta que la actual acumulación por desposesión es la de una ruptura del contrato social, o la reestructuración de las relaciones entre Estado y Sociedad, que posibilita un nuevo cercamiento de los comunes y nuevas esferas de mercantilización. Esto nos permite realizar una lectura diferente y transversal de los procesos de reestructuración del Estado de Bienestar que se están realizando a partir de la crisis mundial del 2007 y la multitud de recortes en salud, educación, transportes... ejecutados en nombre de la austeridad en nuestros entornos más cercanos.

\section{El diálogo entre la economía colaborativa y las emociones}

Nos encontramos ante un escenario de crisis estructural en el cual podemos afirmar que los alegatos hacia el discurso colaborativo van en aumento. Se palpa un estallido de los proyectos de "lo co-», entendiendo dicha abreviatura por resumen de movimientos y proyectos comunitarios, colaborativos y cooperativos. Los cambios e incertidumbres acaecidos junto con toda la respuesta movilizadora social activada ante ese descontento, han llevado a legitimar escenarios co- 
laborativos como territorios de proximidad y sostenibilidad deseados por una parte amplia de la población ${ }^{2}$. Éstos movimientos han compartido escena, sin embargo, con la aparición de una nueva ola de emprendizaje encarnada en las famosas Start Ups que, apoyadas en el soporte tecnológico de las nuevas tecnologías y plataformas de internet, ofrecen un modelo de producción y consumo casi instantáneo, con pocos mediadores y de alta adaptabilidad al consumidor que también ha recibido el nombre de Economía Colaborativa y Consumo Colaborativo. Estos procesos coetáneos viven polémicos e interesantes mestizajes, de los cuales destacaremos uno en concreto: el papel de las emociones en las economías colaborativas.

Una de las hipótesis más polémicas con las que abrimos el debate subyace en la propuesta de la autora estadounidense Eva Illouz (2011) que presenta las coincidencias no intencionales que han surgido entre el feminismo y la terapia positivista. Ejercicios que ha llevado según la autora, sobre todo a las clases medias, a comportamientos metódicos y de control emocional ejercidos mediante el intelecto.

Estos diversos actores [feministas, terapeutas, compañías farmacéuticas...], han convergido en la creación de un ámbito de acción en el cual la salud mental y emocional es la principal mercancía que circula, un ámbito que marca a su vez los límites de un "campo emocional», esto es, una esfera de la vida social en la que el Estado, la academia, distintos segmentos de las industrias culturales, grupos de profesionales acreditados por el Estado y por las universidades y el gran mercado de los medicamentos y la cultura popular se han cruzado y han creado un dominio de acción con su propio lenguaje, sus propias reglas, sus propios objetos y sus propios límites (Illouz, 2011: 219).

En la nueva era del trabajo contemporáneo y lo que podemos considerar como su buque insignia (la Economía Colaborativa), la flexibilidad, la adaptabilidad al consumidor y la rapidez de las demandas de mercado son elementos indispensables. El paradigma del "tiempo es oro", difundido por Benjamin Frankling queda obsoleto y transformado en la idea de que todo aquello que no

2 Estas dinámicas hacia lo co- se reflejan en los proyectos como Los Movimientos colectivos de Repoblación Rural como la Red Ibérica de Ecoaldeas (RIE) en su labor para acabar con la despoblación rural planteando proyectos de vida sostenibles y colectivos. Sindicatos de inquilinas, movimientos pro-viviendas comunitarias o cohousings que plantean la vida en comunidad imbricando arquitectura y comunidad vecinal. Las cooperativas de consumidores de energía (SomEnergia, Goiener) o la alianza contra la pobreza energética, en lo referente a la colectivización y aprovisionamiento del derecho a la energía. El surgimiento de sindicatos de manteros, sindicatos de trabajadoras del hogar (SindiHogar, Territorio Doméstico) y sindicatos de prostitutas que abren nuevos debates sobre el concepto trabajo y la regularización/protección de los derechos laborales. Las redes de soberanía alimentaria y soberanía lingüística (Errigora), redes de consumo de proximidad (Km0) y cestas ecológicas (Bajo el Asfalto Está la Huerta, Me Planto, Berton Bertokoa...) que plantean el abastecimiento de pueblos y ciudades desde la sostenibilidad ecológica y el compromiso colectivo. 
está en movimiento, es dinero perdido (Mogollon y Legarreta, 2015). En resumen, el mantra que la Economía Colaborativa ha sabido recoger es el de que aquello que no se mueve, es un activo en desuso.

Consideramos estos empleos novedosos de lo colaborativo como la punta de lanza de prácticas laborales que poco a poco se van extendiendo en el mercado-laboral global. Éstos van, a su vez e indiscutiblemente, de la mano de lo que se denomina como Nuevas Economías de la Comunicación o Capitalismo Tecnológico como una de las facetas de este poliforme capitalismo que también se denomina financiero, deudocrático, ecocida etc., Centrándonos sin embargo en esta pequeña vertiente, una de las primeras referencias al respecto serán las de Joseph Pine y James Gilmore (1991), los cuales en su obra introdujeron el término economias de la experiencia, siendo así precursores de toda la ola de la economía colaborativa y capitalismo de las emociones (Hochschild, 1995, Illouz, 2011) que acontecería en las siguientes décadas. De este modo, en estas Economías Colaborativas serán los beneficios intangibles que ofrecen los nuevos modelos laborales los que aportan un valor distintivo (Revista Opciones, 2013). Nos referimos a las experiencias, los tejidos sociales momentáneos y fugaces que emergen, las emociones que implican, la sensación de exclusividad y novedad del consumo... Destacan los ejercicios de prosumición que ofrecen la capacidad de creación del producto entre los productores y los consumidores del mismo (Gill, 2016) al instante, y la red que se teje entre los consumidores y los productores a ambos lados de la transacción (Diaz-foncea, Marcuello, y Monreal, 2015).

Pareciera que, en estas últimas décadas de historia contemporánea, el valor y significado de las emociones en la sociedad, se encuentra en un proceso de cambio de posicionamiento y estatus social. Las emociones han pasado de ser un tema tabú (nexo de unión del ser humano a su parte más irracional e instintiva que ha de ser reprimida), a uno de los temas de conversación y teorización más demandados por la audiencia. Evidencian estas transformaciones, entre otros, el surgimiento de "los nuevos modelos de liderazgos» o "las nuevas masculinidades», en los cuales emociones como la empatía, la calma, la amabilidad y el cuidado hacia las personas y los grupos, cobran relevancia frente a la severidad, racionalidad, autoritarismo, seriedad y arrogancia prevalentes de modelos anteriores.

La masificación de los libros de autoayuda, han llevado a algunos colectivos como Espai en Blanc ${ }^{3}$ (2007), a hablar de sociedad terapéutica. Elena Berberana (2018), arroja datos esclarecedores al respecto en la revista digital Libre Mercado al describirnos cómo, en 2016, se llegaron a vender 9.9 millones de ejemplares registrados en la temática de autoayuda y desarrollo personal, cuya factura-

3 Colectivo de pensamiento crítico, colectivo y experimental creado en Les Naus (Barcelona) en el 2002. Se autodefine como brecha entre el activismo y la academia, la teoría y la práctica (ver Spainblanc.net). 
ción ascendió a 119 millones de euros ${ }^{4}$. Mientras, los ejemplares dedicados a la divulgación, psicología, salud mental y medicina, alcanzaron las cifras de 135, 5 millones de euros. En total, desde el 2012 hasta el 2017, se habla de un incremento anual del $2,6 \%$ en dichas materias.

Las hipótesis sobre las causas de la emocionalización de la vida pública varían; desde las teorías de la socióloga Patricia Clough (2007), que sitúa dicho fenómeno en la postguerra y sus efectos en la cultura, la política y la economía, pasando por autoras como Corinne Squire (2001), que hablan de sociedades afectivas, hasta referentes como Eva Illouz (2007:227-228), que definen como capitalismo emocional a esta nueva era social. Dentro de las ciencias sociales, por su parte, se hace referencia al Giro afectivo o affective turn, éste viene a poner en relieve la crítica propiciada por Brian Massumi (2002) y reivindica el ejercicio Spinozano de dejarse afectar y ser afectado en las ciencias sociales. Se podría resumir como «El rescate de las emociones del secuestro biologicista, del uso y estudio exclusivo de las ciencias duras» (Alí y Giazu, 2013: 104).

De este modo, podemos concluir que las emociones están cada vez más presentes y que vienen, sin duda, para quedarse. El impacto de las emociones en el ámbito laboral, sin embargo, no será del mismo calibre en todas las áreas, y es, una vez más, en la Economía Colaborativa, donde observamos una mayor resiliencia a adoptar prácticas discursivas emocionales muy marcadas frente a otras instituciones como pueden ser, por ejemplo, las administraciones públicas, entre otras.

En este camino, las teorías sobre el valor de las emociones y los trabajos domésticos, la ética de los cuidados y los afectos planteados por el feminismo que permitieron ampliar el imaginario social son en estos tiempos absorbidas y disputadas dentro de una cultura global en la cual todas las utopías sobre la felicidad se encuentran atravesadas por el consumo (Ehrenreich, 2011). El consumo, a su vez, pasa a ser entendido como experiencia, elemento que le dará un matiz inmaterial y emotivo diferenciador a las absorciones capitalistas. Se genera un cruce entre emoción y lógica instrumental, se reorganizan las culturas emocionales, haciendo que "el individuo económico se volviera emocional y que las emociones se vincularan de manera más estrecha con la acción instrumental» (Illouz, 2007; 43).

Tal y como resumen Eudald Espluga, Berta Gómez y Santo Tomás (2018) al calor de estas instrumentalizaciones emocionales en un artículo para el diario El Salto en su edición digital, el alineamiento entre la ética de los cuidados y los nuevos discursos de la empresa que se generan en estas Economías Colaborativas es profundo y trastoca de forma radical los significados y contenidos de la intimidad, las emociones y los cuidados:

${ }^{4}$ Datos del jefe de prensa de la Federación de Gremios de Editores de España (FGEE) Gerardo de Miguel, en 2016. 
no sólo la comunicación se ha transformado en un intercambio interesado de información; también el reconocimiento de la fragilidad y la dependencia ha dado paso a ideales más complejos de autosuficiencia; la imaginación y el pensamiento narrativo se han convertido en formas de capital creativo; la atención y la confianza son vistas como competencias para mejorar la eficiencia de un equipo y no como un espacio de resistencia a la lógica del mercado; y la autonomía, lejos de ser entendida como la capacidad de tejer nuevas relaciones, se define como la posibilidad de aislarse de los demás.

En nuestro marco de análisis, subrayamos el papel y disputa de emociones como el apego, la pasión y el deseo hacia el trabajo-empleo dentro del entramado de absorciones e instrumentalizaciones capitalistas propiciadas por el mundo de lo colaborativo, pues, como veremos a continuación en el tercer apartado, no todas las emociones tendrán el mismo peso o aceptación social. Así mismo, en el marco de los empleos de las Economías Colaborativas las actividades laborales rebosan el espacio laboral para introducirse de lleno en un aspecto de peso de la vida de sus participantes, no solamente a nivel de recursos materiales y poder adquisitivo, sino también a nivel psicológico-emocional. Son las energías comunicativas, las capacidades creativas, la pasión, el humor, el ingenio, la empatía, lo más brillante de las capacidades intelectuales y vitales, lo que se pone a disposición de la empresa en todo el proceso productivo y laboral. Como consecuencia, «la empresa (independientemente de la relación jurídica entre propiedad y trabajo) tiende a ser el núcleo en torno al cual se infiltra el deseo, el objeto de una inversión ya no solo económica, sino también psíquica» (Morini, 2014: 93). Uno de los alegatos o iconos más característicos en este sentido abanderado por las Economías Colaborativas son las famosas frases de Confucio sobre «Escoge un trabajo que te guste, y nunca tendrás que trabajar ni un solo día más en tu vida» o la de Winston Churchill de «Esfuerzo continuo, no fuerza o inteligencia, es la clave para liberar nuestro potencial».

Esta atención en el control afectivo y las reglas emocionales (feeling rules), no es algo novedoso, aunque sí es destacable el incremento y expansión de su interés gracias al avance y fama de esta Economía Colaborativa. Arlie Hochschild (2001), nos habla de cómo cada situación social induce a un conjunto de emociones en los actores sociales, pautadas y normativizadas, que especifican la intensidad, dirección y duración del sentimiento. Evoca un sinfín de situaciones sociales (rupturas, embarazos, discusiones, situaciones dramáticas...), en las cuales se encuentran social e implícitamente marcados los plazos y sentimientos específicos que ha de tener cada individuo. De este modo, visibiliza cómo se encuentran estipulados los códigos de la cultura emocional de cada sociedad como, por ejemplo, cuánto es el plazo de «lamento» por la ruptura de una relación y cuándo se está siendo "exagerado/a», cómo ha de sentirse una mujer que acaba de ser madre en los primeros años de su bebé (emocionada, extasiada, agradecida, completada...) o cómo no ha de sentirse (harta, depresiva, enojada, as- 
queada, arrepentida...). En este último caso, un libro altamente recomendable que refleja los mecanismos de control afectivo y reglas emocionales en el universo maternal, es el de "Madres arrepentidas: una mirada radical a la maternidad y sus falacias sociales» (Donath, 2016) y su estudio sobre la maternidad desafecta.

En el marco de la Economía Colaborativa el control social arremete de forma exquisita en materia sentimental y afectiva, apropiándose y contorneando dimensiones emocionales de la vida, pues no bastará con ser eficaz en el trabajo y respetuoso en las relaciones, habrá de ser motivador, apasionado, cercano, carismática, efectiva, asertiva... Esta vinculación entre emoción y ejercicio productivo, genera lo que diversas autoras definirán como la reconquista del tiempo de vida por parte del capital (Valenzuela y Bruquetas, 2015; Berardi, 2016).

Permite ampliar el trabajo-empleo y la producción a cualquier hora del día gracias al innegable apoyo de dos dispositivos decisivos: el teléfono móvil e internet. Estos abren en canal la intimidad y el tiempo libre de las personas trabajadoras, convirtiéndolas en localizables en todo momento y lugar, susceptibles a ser llamadas a desarrollar su función productiva. De hecho, la instantaneidad del consumo y de la atención individualizada hacia la demanda del cliente se convierte en estas Economías Colaborativas en un rasgo distintivo y necesario de la relación entre consumidora y productora. De este modo, se pavimenta la opción de «absorber cada átomo posible de tiempo productivo en el momento exacto en que el ciclo productivo lo necesita, y así disponer de la jornada entera del trabajador, remunerando tan solo los momentos en los que es celulizado» (Berardi, 2016).

Como consecuencia de esa invasión por parte del capital, observamos el fenómeno de la colonización del cliente (Gold y Mustafa, 2013), recogido sobre todo en las y los trabajadores freelance. Nos retratan a una trabajadora de lo colaborativo que no es capaz de controlar los ciclos de demanda de trabajos, completamente dualizada entre el estrés de mantener la demanda y llegar a los plazos de forma óptima y la auto-culpabilización cuando esta decrece y el trabajo comienza a no ir como necesita. Igualmente, junto con la competitividad extrema, también se narra la «realización frecuente de trabajos "para comer» poco gratificantes y poco creativos» (Ortega, 2018: 28)

En estos empleos colaborativos se observa cómo acontece la transformación del tiempo de trabajo, que muta de ser un trabajo estipulado dentro de cierta jornada laboral (partida, continuada, a turnos, nocturna...) y su posibilidad de horas extra, a ser un tiempo de trabajo informe, basado en el ideal del sujeto de rendimiento total (Chul Han, 2012). Este modelo de trabajador o trabajadora $\mathrm{BBVAh}^{5}$ se caracteriza por tener una productividad siempre lineal, autónoma y

\footnotetext{
5 Este término resume los privilegios que en nuestras sociedades patriarcales actuales destilan algunas categorías sociales frente a otras. Es un eje central de la literatura de la economía feminista
} 
ascendente. Un tiempo de trabajo hecho a imagen y semejanza de una trabajadora que no enferma, que no tiene que cuidar a nadie, sin altibajos, inagotable, en constante formación, motivación y disponibilidad.

A este fenómeno de flexibilidad total de la jornada laboral y su expansión a cualquier hora del día de la vida de sus trabajadoras se lo conocerá bajo el modelo 24/7: 24 horas al día, 7 días a la semana proclamado desde un movimiento difundido por los hackers de Silicon Valley en los años noventa bajo su lema de "24 hours a week and I love it» (Crary, 2014). Dicho modelo será sin lugar a dudas el del trabajo icónico dentro de la Economía Colaborativa y el Capitalismo Tecnológico, aquel caracterizado por una pasión y amor hacia la jornada laboral total, el trabajo esclavo bajo sumisión voluntaria en nombre de la pasión y la ilusión de un proyecto de vida mercantilizado. El 24/7 ha sido un modelo laboral polémico desde sus inicios, pues en ciertos sectores liberales se ha presentado como la medida de conciliación ideal, mientras que otros lo situaban como modelo de explotación absoluta. En cualquiera de las posiciones, se evidencia que este representa una interesante paradoja para los empleos colaborativos, de autopromoción y emprendizaje social, que rodean las capas más jóvenes de la sociedad. Puesto que, ¿cómo no extender la jornada laboral si estos trabajos se encuentran vinculados a emociones tan positivas y expansivas como la pasión, la auto-realización, la solidaridad, el deseo o el apego? ¿Cómo dejar de hacer algo que no considero mi empleo, sino mi pasión, mi hobbie? ¿Cómo poner límites si mis compañeros de trabajo son casi más que amigos, son mi tribu, mi familia?6

Una de las consecuencias detectadas ante esta expansión de la jornada laboral apasionante y que busca ser intencionalmente apasionada, se percibe en la tendencia que torna el tiempo de vida (ocio, cuidados, amores, amistades, tiempo libre...), en dinámicas de producción y adquisición de conocimientos y experiencias relacionadas directamente con el ámbito laboral (Capacitación, 24/7). Así mismo, las agendas de las personas que participan en estos modelos de trabajos novedosos de la Economía Colaborativa rebosan congresos, encuentros, memes, charlas, películas, cenas, teatros, artículos, incluso conciertos y talk shows insertos dentro de las temáticas laborales pertinentes. Contenidos que no

pues permite identificar al sujeto-ideal portador de privilegios de la economía actual centrada en los sujetos Blancos, Burgueses, Varones, Adultos y heterosexuales y bebe de numerosos debates de los Congresos de Economía Feminista, aunque su popularización se debe a Amaia Pérez Orozco (2014). Este tipo ideal se presenta incluso en cuerpos leídos hegemónicamente como mujeres, pues es una estrategia central la de adoptar posiciones y actitudes masculinizadas (aplazar la maternidad o negarla, utilizar una voz más grave, vestimenta andrógina o neutra etc.) para obtener los privilegios de poder que ofrece el acercarse a ese sujeto-ideal androcéntrico tan icónico en nuestras sociedades del empleo (Prieto, 2000).

${ }^{6}$ Los nudos o debates formulados en materia de incógnitas han sido extraídos en ciertas ocasiones y deducidos en otras tantas gracias al trabajo de campo realizado en el marco de la Tesis Doctoral que se está llevando a cabo «Estrategias Colectivas de Sostenibilidad de la Vida en Tiempos de Crisis» por la autora a cargo de la tutorización de Matxalen Legarreta Iza y Mertxe Larrańaga Sarriegi. 
están intrínsecamente unidos a las actividades empresariales, pero que forman parte del universo laboral que rodea a dichas actividades productivas. Todo ello desemboca en un proceso en el cual la empresa acaba definiendo la vida de la trabajadora, desdibujando la diferencia entre la creatividad laboral y personal (Ross, 2003). Como apunta Stefano Harney y Fred Moten (2013), se trata del plusvalor total de la vida y la reconquista capitalista del tiempo de vida. Así mismo, «La puesta a producir de emociones, sentimientos, toda la vida extra-laboral, las redes territoriales y sociales, significa en la práctica que a la persona se la hace productiva por su mera existencia.» (Hoschild, 2008; 93).

Inspirada en la tesis de Charles Wright Mills que allá por 1951 hablaba del alienamiento que sufrían las clases medias trabajadoras estadounidenses con el fenómeno de alienación- burocrática generada en los trabajadores de «cuello blanco", Arlie Hochschild (1983), nos hablará de una nueva paradoja de alienación. En ésta, al vender mediante nuestro trabajo y consumo nuestra personalidad, nos implicamos en un proceso de auto-extrañamiento cada vez más común en los sistemas del capitalismo avanzado.

Sin embargo, ¿qué sucede cuando el extrañamiento o la alienación no es completada? ¿Qué es lo que sucede cuando no se obtienen los comportamientos emocionales exigidos? ¿Cuándo sentimos algo que supuestamente no nos está permitido o no es acertado sentir? ¿Cuándo las emociones consideradas como negativas (el mal humor, los nervios, el estrés, la pena...) invaden nuestras relaciones sociales? ¿Cuándo surgen brechas de disconformidad en ese pensamiento positivo apasionado y proactivo?

La autora, una vez más, analiza esos casos para definirlos como momentos de disonancias o desviaciones emocionales (Hochschild, 1983). Momentos en los que la rabia, el enfado, el cansancio, la tristeza, los nervios, la ansiedad, etc. desbordan las situaciones pautadas. Es justamente en ese hito, ante estas desviaciones, donde surgen nuevas formas de disciplinamiento emocional de la esfera humana que hasta la fecha no habían sido capturados por los manuales de empresa y recursos humanos: la gestión emocional o el emotion management dentro del marco de la retórica positivista.

Un positivismo arrollador, que empapa desde frases decorativas del hogar (cuadros, cojines, tazas de café...) vendidas por grandes superficies como Ikea, hasta frases de tatuajes-mainstream con los que la gente marca su cuerpo de por vida, pasando por publicaciones de fotografías en las redes sociales llenas de mensajes motivacionales adscritos a alguna eminencia pública (escritores, actrices, poetas, físicos...).

Como trabajaremos en las siguientes líneas, el mensaje de estos procesos de gestión emocional es contundente: no basta con hacer algo, hay que sentirlo y, si no es así, «"tratamos de sentir algo», hacemos esfuerzos por modificar nuestros 
estados emocionales» (Bericat, 2000:161-162). Es justamente en ese momento donde la creciente demanda de manuales de autoayuda, el mind fullness, las metodologías participativas y colaborativas, las terapias gestlálquicas, las gestiones grupales, las inteligencias colectivas, los facilitadores grupales o coach-es, cobran relevancia dentro del proceso productivo capitalista.

\section{Un último aliciente: El pensamiento positivo}

\section{La psicopolitica neoliberal es una politica inteligente que busca agradar en lugar de someter (Han, 2014: 57). \\ el poder se legitima siendo afectivo y efectivo (Espluga, Gómez y Tomás, 2018).}

El pensamiento positivo como corriente dominante que se filtra en una infinidad de corrientes psicoterapéuticas masificadas (mindfullness, coaching, PNL, Gestalt...), presenta conceptos en contraposición como, por ejemplo, mirar a las abundancias en vez de a las carencias, promover la positividad en vez de la negatividad, buscar el aprendizaje en vez del fracaso etc.

Si bien las emociones toman un papel central para la producción de capitales sobre todo en las Economías Colaborativas y los mercados dibujados bajo el Capitalismo Tecnológico, como ya se ha comentado, no todas las emociones tendrán el mismo peso y reconocimiento en el marco actual de los modelos laborales de lo co- . Serán emociones como la pasión, el apego, la felicidad, la confianza, la ilusión, la empatía o la dulzura, las que primarán frente a la tristeza, el dolor, la frustración, el enfado o la rabia. Para poder sostener esta jerarquía emocional, la gestión emocional o el emotion managment, cobrará un papel central, destacando la corriente teórica del Pensamiento Positivo (Ehrenreich, 2011) como aparato de control y doma emocional.

Esta corriente de pensamiento ha popularizado tanto los discursos de austeridad y positividad, como los del cálculo racional de las emociones. En consecuencia, el espacio público y laboral de estas Economías Colaborativas se encuentra repleto de discursos semejantes a "solo con sacrificios se consiguen los sueños», «Es difícil, pero caminando juntas lo conseguiremos», "creo que esa persona es tóxica para ti», «renovarse o morir», «despréndete de la gente con actitud negativa pues son agujeros emocionales", "salir de la zona de confort», "es duro, pero no cambiaría nada de mi trabajo porque me aporta mucho» o «los retos y las caídas te harán crecer como persona, desde la comodidad no se construye nada nuevo».

De la mano de estos discursos, las jóvenes y no tan jóvenes trabajadoras y trabajadores colaborativos, se introducen en la maraña de prácticas de au- 
topromoción y consumo, invirtiendo en promesas de mejores futuros y convirtiendo en trabajo la producción de si mismos (Morini, 2014). Uno de los mantras más consolidado al respecto en la Economía Colaborativa es el de "yo soy mi propia marca» o "yo soy la mejor publicidad de mí mismo». Así mismo, las plataformas digitales se convierten en centrales en la autopromoción del trabajo de cada uno y el estatus social pasa por abrir los focos de la escena digital a cierta parte de lo que hasta el momento se consideraba intimidad; desde las vacaciones con los amigos en un festival, hasta la foto de la comida de hoy pasando por "marcas deportivas» propias como son el mapa del recorrido y cuántos kilómetros se ha corrido en su hora de deporte, todo se transforma en "publicable». Boltanski y Chiapello (2002) al respecto afirman que este tipo de corrientes generan lo que definen como sumisión voluntaria, dado que en la actualidad el individuo, bajo una sobre-estimulación constante, comparte y produce información en torno a sí mismo sin necesidad de tener que extraerla a la fuerza o comprar dicha mercancía. Como recogíamos en líneas anteriores, estas lógicas positivistas, apoyadas en los novedosos dispositivos tecnológicos de Internet y los Smartphone-s permiten abrir en canal la intimidad y el tiempo libre de las personas trabajadoras, transformando todo momento vital en susceptible a desarrollar su función productiva. De este modo, en la Economía Colaborativa ya no será necesario ni siquiera el uso de una página web, bastará con tener una bonita cuenta de Instagram, Twitter o Facebook siempre activa y disponible para cualquier demanda de consumo.

Este nuevo orden biopolítico, se impulsa por «el nacimiento y consolidación de la psicología, cuya principal característica es gobernar la vida por medio del discurso terapéutico» (Zapata, 2019; 87). Como consecuencia, lo que desde este orden discursivo positivista y colaborativo se nos transmite es la idea de que será el individuo o la persona (el hiper-protagonismo del yo), la única responsable de las acciones para emprender y cambiar las situaciones de sufrimiento que la rodean. A su vez, al generarse esa individualización de la responsabilidad social, la patologización de cada situación resultará más sencilla, dado que comenzará a interpretarse la desigualdad social y económica y todos «esos malestares sociales encarnados como una mala salud emocional de individuos concretos» (Zapata, 2019: 88), y es que no hay más contabilizar las escasas posibilidades que tienen los sindicatos tradicionales para articularse en estas cooperativas e incluso grandes empresas como Uber, AIRBNB, Cabify o Amazon de lo "Colaborativo».

Esta idea de que es la trabajadora la única responsable de su situación laboral y vital conectará con lo que para nosotras es la cara oculta del artefacto emocional de las prácticas discursivas del pensamiento positivo: la culpa. Una culpa que asume la narrativa de "no haber creído lo suficiente en el proyecto», "no haberse esforzado cuando tocaba», "no haber tenido esa genial idea" o "no ser lo suficientemente genuina en lo tuyo». 
Volviendo a las palabras referentes de Arlie Hochschild (2001), cuando entra en juego la gestión emocional tan característica de las prácticas de la Economía Colaborativa, ésta deja de ser considerada un acto privado para convertirse en Trabajos emocionales que cada individuo deberá realizar, comprendido dentro del orden de habilidades laborales y de capacitación. Los sindicatos de trabajadoras y trabajadores quedan relegados frente a los grupos de trabajo tipo comunicación grupal, charlas motivacionales como las famosas Charlas Ted, los talleres con terapeutas o coaches grupales, etc. De este modo, los conflictos laborales y las situaciones materiales son atajados, modificando «directamente el sentimiento por medio de cambios en nuestro foco perceptivo sobre la situación, o por acciones fisiológicas, como puede ser respirar profundamente para calmarse» (Bericay, 2000: 163). En resumidas cuentas, dado que la estructura social y sus condiciones materiales se convierten en innegociables en estas Economías Colaborativas y ante la crisis estructural actual, el planteamiento transmitido insta a transformar la manera que tenemos de ver dichas situaciones (pensamientos) o la forma en que tenemos de sostenerla en el momento (prácticas).

Las corrientes del pensamiento positivo se pavimentan en la idea de que cada cual obtiene en la medida en la que emana. Bajo esta idea de acción-reacción racional tan básica, se recoge el argumento de que el beneficio del usuario se sitúa en el centro, incluso por encima de, en ciertos casos, los ingresos de la propia empresa. Todo ello, bajo la promesa de que «... si el usuario está contento, la demanda crecerá y la rentabilidad llegará antes o después.» (C.Otto, extraido de El Confidencial el 23/07/2018). De este modo, es el trabajador o empresaria la que "atrae» lo que quiere en su negocio y no espera a que llegue «fortuitamente».

Ciertamente, esta promesa rememora la teoría de la filtración defendida por los economistas neoliberales, que postula que la riqueza acumulada de los grandes capitales es positiva para toda la sociedad, puesto que finalmente estas grandes fortunas terminan filtrándose, «de alguna forma», a todas las clases sociales. Con esta hipótesis se pavimenta la idea de que las grandes riquezas terminan «equilibrándose» en una riqueza colectiva. Esta teoría fue ampliamente rebatida por diversos economistas, entre los que se encontraba Joseph Stiglitz, que afirmó justamente que "el crecimiento no beneficia necesariamente a todos» (Sitglitz, 2002;108). Puesto que la equidad y la igualdad, son postulados que recorren otros caminos político-económicos que se alejan del laissez faire, laissez passer económico liberal.

Otra idea latente que recoge el pensamiento positivo es la de austeridad y sacrificio. Gracias a lo que hemos denominado como «el cuento colaborativo de la lechera", se permite abrir las puertas de par en par a la normalización de la precarización de las condiciones laborales. Se alcanza mediante el ejercicio constante de relativización de los sueldos percibidos y los horarios de trabajo. Ejercicio 
encumbrado gracias a los discursos que enarbolan otros tipos de remuneración, como pueden ser el reconocimiento social, las experiencias curriculares, el capital simbólico, o el enriquecimiento vital del trabajo (Florida, 2010). Se encarna en el que podríamos denominar como el sindrome del eterno becario, esa figura laboral cuyo sueldo o condiciones laborales son precarias, pero son justificadas bajo el argumento de que al fin y al cabo se está obteniendo experiencia, conocimientos, habilidades y currículum para el trabajo estable del futuro.

Aquí podemos observar cómo se rozan las paradojas de los modelos económicos más salvajes de la Economía Colaborativa con las teorías de los movimientos feministas. Mientras estas últimas proclaman la valorización de otros elementos más allá del dinero, como puede ser el reconocimiento social, el crecimiento personal, las vivencias, las compatibilidades temporales y conocimientos adquiridos etc. el Capitalismo Tecnológico se los apropia para justificar y perpetuar la pauperización laboral de sus trabajadoras.

La otra moneda de la precarización serán las nuevas vías de estigmatización de los cuerpos (López, 2016). Siendo afectados los cuerpos más vulnerables e inadaptables a jornadas laborales infinitas o con responsabilidades familiares ${ }^{7}$ que les impiden incurrir en la disponibilidad total hacia la empresa. Disponibilidad indispensable en el ejercicio de colaborar, de cercanía, de predisposición que presentan estos empleos, que llevan a poder responder, por ejemplo, una ráfaga de e-mail de última hora a las 00:30 de la noche desde nuestro Smart-Watch o a poder tomarse unas cañas post-reunión de trabajo a las 20:00 de la tarde en la que se debate sobre asuntos laborales y promociones. Dicha estigmatización de los cuerpos, profundiza los privilegios de los sujetos de rendimiento total (BBVAh), pues no todo el mundo puede estar con una disponibilidad 24/7 hacia el empleo, sobre todo en caso de responsabilidades de cuidados en primera persona o a terceras personas (familiares con enfermedades crónicas, criaturas etc.). Esto provoca, por una parte, que tanto las personas con responsabilidades de cuidado como los cuerpos predecibles de culturas laborales antiguas y menos eficientes, sean "políticamente neutralizados, por su escasa posibilidad de «reutilización» y su incapacidad para producir «ciclos cortos de rendimiento máximo»" (Landa y Marengo, 2010; 82).

La precarización de las condiciones laborales en esta Economía Colaborativa cambia el tablero de la estabilidad deseada y las proclamas de derechos. Así, lo que a principios de siglo era una queja, como puede ser el mileurismo, hoy en día torna a ser un escenario deseado. El salario se desestructura, y el impacto en las

7 Queremos hacer consciente la decisión de la no utilización del término «carga familiar» pues consideramos que implica una significación que no compartimos ideológicamente. Si a las responsabilidades del trabajo-empleo no se les llama "cargas laborales» por muy forzosas en tiempo, energía y dedicación que sean, consideramos que el ejercicio de las diferentes dependencias y cuidados merece compartir la misma categoría semiótica. 
condiciones de vida de este cambio es total. A diferencia de los «caros y tradicionales puestos de trabajo» (Piñeiro, Suriñach y Fernández, 2017: 106), la responsabilidad de la cobertura asistencial de la jubilación, vacaciones pagadas o enfermedad, se desdibuja de los denominados costos indirectos del trabajo, generando así una individualización de los costes y los riesgos de ser empleada y empleado. Como resultado tenemos un proceso que abarca territorios más amplios que los colaborativos, pero que sin duda los empapa, puesto que:

Corremos el riesgo de pasar del autoritarismo financiero, a la nueva tiranía de los algoritmos y las plataformas, que bajo la apariencia de la economía de la colaboración y de la ilusión de la promesa de la libertad digital, monopolizan y priorizan la información según sus intereses, además de precarizar los mercados laborales (Solanilla, 21/11/2018).

Como ya se ha apuntado, los riesgos que encarnan estas precarizaciones de las condiciones de trabajo de las Economías Colaborativas tan icretumban en la creciente despolitización de los espacios laborales y la constante «omisión de la capacidad de hacer pensable la conexión entre la vulnerabilidad en el trabajo y relaciones políticas de desigualdad» (Serrano y Fernández: 2018, 207). La atomización política del entorno laboral va en aumento y los conflictos colectivos se ven cada vez reducidos, en mayor medida, a vías judiciales individuales, con la consecutiva pérdida de músculo sociopolítico de las y los trabajadores de cada sector. Encontramos cada vez una mayor deriva de la lucha sindical por la mejora de los convenios colectivos a la vía judicial privada para la resolución puntual de una problemática laboral concreta ${ }^{8}$.

Barbara Ehrenreich (2011), en «Sonríe o muere: la trampa del pensamiento positivo", nos narra cómo la nueva gramática del pensamiento positivo anglosajón y, sobre todo, estadounidense desenfoca el desempleo hasta plantearlo como una oportunidad de crecimiento personal. Se trata, ni más ni menos, de la narrativa y justificación de situaciones dolorosas en nombre del crecimiento personal. Hace especial hincapié en los discursos que discurren sobre que «esto me ha pasado porque tenía que aprender algo de esta situación», para subrayar la idea de la individualización de las responsabilidades que acabamos de trabajar, atribuyendo a las corrientes de Pensamiento Positivo, por ejemplo, que planteen el encontrar trabajo como «una cuestión de actitud». Este optimismo obligatorio o alegría obligatoria de la que nos hablará es la que presenta la total capacidad del mundo de los pensamientos para cambiar la realidad material (Ehrenreich, 2011). La autora realiza una dura crítica a este modelo, sobre todo en términos morales, al plantear que individualizar la totalidad de los sucesos sociales a espaldas de cada una de las personas que sufren consecuencias estructurales es

\footnotetext{
${ }^{8}$ Esta reflexión corresponde es fruto de un debate colectivo mantenido con Arritxu Larrańaga, abogada laboralista y sindicalista del sindicato LAB.
} 
mezquino y cruel. Propone, como contraparte, un realismo profundo (Radical Suggestion Realism) basado en un análisis desde las condiciones de realidad y capacidades propias, que impulse, pero no asfixie la capacidad y voluntad individual y colectiva.

\section{Algunas conclusiones}

Dado que a lo largo del texto se han querido dar múltiples brochazos para poder ampliar los elementos del debate en torno al conflicto Capital-Vida, enumeraremos algunas conclusiones al respecto, pero, sobre todo, cerramos el presente artículo lanzando a la arena del debate incógnitas que consideramos interesantes.

Primero, concluimos que la Economía Colaborativa, con sus modelos laborales y económicos, es el ejemplo más marcado del proceso de capitalización del mundo de la vida. Se trata del buque insignia, la punta de lanza de un proceso global de diferentes ritmos, pero cuya representación y su divulgación ha venido de la mano del que puede considerarse como «cajón de sastre de lo colaborativo". A este respecto, intuimos, al igual que apuntan diversas autoras, que se está produciendo una nueva oleada de acumulación por desposesión, generada por un desplazamiento de la relación capital/trabajo hacia una relación capitall vida (Corsani, 2002) con características muy específicas e íntimamente relacionada con el sector de vanguardia de la Economía Colaborativa.

En resumen, dentro de la maquinaria de absorción del capitalismo tecnológico, el trabajo-empleo resulta insuficiente para el capital, éste necesita nuevos territorios de absorción, y escoge la vida, con sus relaciones de mayor intimidad, creatividad y cuidados, como nueva relación económica de captura. Estos espacios de vida se extienden como apéndices de la jornada laboral continuada 24/7, apoyándose en emociones tan pegajosas y positivas como la pasión y la felicidad como elementos de sumisión voluntaria hacia una producción y sujetos de rendimiento total. Consideramos que, desde el feminismo y la economía feminista, deberíamos plantear estos escenarios como nuevos retos para el debate sobre los límites de la vida; ¿cuáles son los límites temporales, límites emocionales, límites relacionales... que nos permitirán dibujar unas líneas rojas necesarias para la sostenibilidad de la vida? ¿Cómo identificarlos y consensuarlos? ¿Mediante qué sujetos (sindicatos, estado, trabajadoras, consumidoras...)?

En un mundo donde cada vez con mayor impunidad «todo vale» en el ejercicio de la producción de mercancías, consideramos que se debe reivindicar una negativa profunda y unas necesarias divisiones entre lo que es mercantilizable y lo que no a la hora de hablar de la vida. Y es que, si queremos vidas vivibles y sostenibles con condiciones laborales dignas, vamos a tener que 
ir sentando precedentes en lo que a la digitalización de las relaciones sociales y laborales se refiere. Este proceso, sin embargo, presenta múltiples dificultades, pues podría concluirse en una primera lectura superficial de los hechos, que las emociones o los empleos colaborativos son, de por sí, los «demonios» de nuestra sociedad contemporánea. Por el contrario, consideramos que es el acento, o la pregunta de ¿al servicio de qué disponemos nuestras emociones y nuestra ética colaborativa? lo que debe situarse en el centro del debate social.

Destacamos, por ejemplo, dentro del debate sobre la digitalización de las condiciones laborales la polémica en torno a las horas extra, pues en la economía colaborativa se extiende el universo laboral hacia actividades como el networking, la capacitación-formación e innovación constante, el valor de la inmediatez... uno de los riesgos adscritos a estas características reside en la ingente cantidad de horas extra no pagadas que acarrea. En tal caso, el debate sobre los límites se dirigiría hacia ipuede ser el o la trabajadora en todo momento celulizable? ¿tiene el o la trabajadora derecho a tener una jornada laboral definida y pautada? ¿cómo establecer en la era de las nuevas tecnologías horarios laborales sostenibles? ¿tiene la trabajadora derecho a ser apática, distante, correcta o ha de ser siempre cercana, alegre, afectuosa?

La segunda conclusión remarcable será la de la individualización de la responsabilidad social, que consideramos piedra angular en la precarización de la vida y las condiciones laborales en este modelo de Economías Colaborativas. La lectura de los acontecimientos vira, y nuestras condiciones laborales y vitales no concuerdan con las narrativas sobre la explotación, ya no tenemos conflictos laborales derivados, entre otros, del roce del proceso de producción, intereses de extracción y los ritmos del mercado. Por el contrario, lo que tendremos en estas economías digitales es gente tóxica o gusanos emocionales, personas que no se han trabajado sus emociones y que necesitan cambiar el foco para poder avanzar en la vida, para verla de una forma más positiva. Una vez más, no quisiéramos caer en falsas dicotomías al respecto y queremos ser muy contundentes en este matiz: consideramos que trabajar las emociones individual y colectivamente es un ejercicio necesario y positivo para el crecimiento personal y colectivo en el proceso de generar espacios y vidas más vivibles e inteligencias colectivas saludables. Sin embargo, este proceso no puede pasar por negar las condiciones materiales y simbólicas en las que se desarrollan los trabajos y las vidas en general. Se debe interpelar, de este modo, no solo al individuo y sus actitudes como factores necesarios del cambio, sino también se ha de apostar por transformar o mejorar las condiciones de vida en el proceso desde una politización de lo cotidiano y lo personal. Si no actuamos en estos parámetros, cabe el riesgo de terminar normalizando e individualizando condiciones laborales precarias y llenas de dominación, extracción y expolio.

Para destacar nuestra tercera conclusión, nos gustaría visibilizar una disputa o lucha que hay entre el sujeto de esta nueva economía colaborativa y el 
sujeto trabajador clásico, contraposición polémica propuesta por ciertos autores (Ortega, 2018). La figura del emprendedor se propone, en esta línea, cual actualización del sujeto hecho a sí mismo (self made man) o BBVAh, despuntando como nuevo modelo laboral, dispuesto a derrocar a lo que considera la lacra del empleado asalariado (Ortega, 2018). Presenta a este empleado asalariado como enjambre de burócratas, ineficientes, ralentizadores del progreso, corporativistas y descuidados. Pareciera que, en los discursos emprendedores, incluso se acusa al trabajador/a asalariada de la crisis económica actual, pues vivieron por encima de sus posibilidades, siendo los y las emprendedoras la única solución a la crisis de las sociedades del empleo (Prieto, 2000). Se concluye que en el discurso emprendedor que inunda la actualidad, el asalariado/a se enfrenta con su máximo representante de la retórica parasitaria: el viejo burócrata.

Ante estos imaginarios, surge la idea del empleo emprendedor, colaborativo, cooperativo, participativo y digitalizado. Fresco, dinámico, joven, atrevido, adaptado, fluido, innovador, valiente, sońador, con el palet de madera como icono de esta era y la estética denominada vintage de colores pastel... Nos gustaría proponer el debate sobre ¿qué hay detrás de este discurso de contraposición? ¿Cuáles son las características de esta nueva era de capitalismo tecnológico que marida con el capitalismo de las emociones y las teorías del new age terapéutico como el pensamiento positivo? Y, sobre todo, ¿qué consecuencias trae el modelo de emprendizaje en las condiciones de vida de las personas que lo llevan a cabo?

A modo de cuarta conclusión, apuntamos a toda la retórica sobre el emotional managment como potencial herramienta disciplinadora, contenedor emocional y social de situaciones de profunda precariedad. No quisiéramos plantear una visión catastrofista en la que hablar de las emociones sea per se un ejercicio de alienación y absorción capitalista de nuestras capacidades y emotividades, más sí reivindicamos el necesario ejercicio de perdida de la inocencia ante estos escenarios. Dado que la maquinaria de absorción capitalista tiene el potencial de abastecerse de retóricas feministas en torno a los cuidados, la conciliación, la igualdad, la pasión, el trabajo colectivo e incluso la responsabilidad con el medio ambiente y transformarlas para su capitalización. Un ejemplo bastante icónico de este tipo de estrategias son los denominados Washing-s o procesos de lavado, pinkwashing, greenwashing, blackwashing, entre otros, o los sistemas de ocultación de malas prácticas y estrategias retrógradas bajo rostros amigables hacia ciertos movimientos sociales como el ecologismo, el movimiento LGTB etc. En este sentido, si nuestro objetivo es poner la sostenibilidad de la vida en el centro de la actividad social, uno de los caminos por recorrer reside en convertir nuestras empresas y espacios laborales profundamente en entornos más vivibles, y no, por el contrario, nuestras vidas y luchas personales y colectivas más laborables, empresarializables o consumibles. 
Entendemos por vivibles el desarrollo de espacios más humanos y resilientes ante las vulnerabilidades y necesidades colectivas e individuales que nos acompañan a lo largo de toda la vida en diferente medida. Destacamos, en este punto, la desprotección y falta de recursos colectivos que identificamos para leer estas relaciones peligrosas de doma emocional y manipulación en el entorno laboral y en el consumo. No es un debate menor, pues el nivel de fidelización y sumisión voluntaria que generan tanto las empresas como las marcas al atravesar todo el proceso con una estrategia emocional de alta intensidad es considerable. Volvemos a lanzar preguntas al aire al respecto ¿Cómo tomar conciencia y empoderarse en este tipo de dinámicas de retóricas tan seductoras?, ¿Cómo analizar las consecuencias de vendernos experiencias en vez de productos?

Finalmente, reflexionando sobre las posibles estrategias de sostenibilidad de la vida a recorrer en estas novedosas etapas del conflicto Capital-Vida, quisiéramos traer la provocadora tesis planteada por Alfredo Macías (2017): en esta fase del capitalismo, las personas se encuentran condicionadas por categorías abstractas y cotidianas que pautan su comportamiento, por lo tanto, mirar a los partidos políticos a la hora de buscar soluciones será un ejercicio inacabado. Se defiende, de este modo, que solamente basándonos en un análisis profundo de las tendencias y comportamientos actuales (lógicas relacionales, de consumo y ejercicios emocionales, entre otras) podremos plantear soluciones integrales.

\section{Bibliografía}

AlbaRRAcín, Jesús (2010): «La extracción del excedente y el proceso de acumulación»en Miren Etxezarreta (coord..) La reestructuración del capitalismo en España, pp: 331-332.

Alí, Lara, Giazú, Enciso Domínguez (2013): «El Giro Afectivo». Athenea Digital, 13(3), 101-119. http://dx.doi.org / 10.5565/rev/athenead/v13n3.1060

Benería, Lourdes (1999): «El debate inconcluso sobre el trabajo no remunerado» Revista Internacional del Trabajo, vol. 118, n.o 3, 321-346.

-2008): «The Crisis of Care, International Migration, and Public Policy», Feminist Economics, 14 (3), 1-21.

Berardi, Franco (2016): Almas al trabajo: alienación, extrañamiento, autonomía. Madrid: Enclave.

Berberena, Elena (2016): «La libertad también se vende: los libros de autoayuda mueven cientos de millones de euros», Libre Mercado, extraído el 10/01/2017 en https://www. libremercado.com/2018-04-11/la-felicidad-tambien-se-vende-los-libros-de-autoayuda-mueven-cientos-de-millones-de-euros-1276616836/

Boltanski, Luke, Chiapello, Éve (2002): El nuevo espíritu del capitalismo. Buenos Aires: Akal.

Borderías, Cristina, Carrasco, Cristina y Alemany, Carmen (comp.) (1994): Las mujeres y el trabajo. Rupturas conceptuales. Barcelona: Icaria.

CASTELLs, Manuel (2006): La sociedad Red: Una visión global. Editorial: Alianza.

Carrasco, Cristina (1991): El trabajo doméstico. Un análisis económico. Ministerio de Trabajo y Seguridad Social. Madrid. 
- (20 I7): «La economía feminista. Un recorrido a través del concepto de reproducción», Ekonomiaz, n. ${ }^{\circ 91}$ 1-26.

CARrasquer, Pilar (2013): «El redescubrimiento del trabajo de cuidados: algunas reflexiones desde la sociología», Cuadernos de Relaciones Laborales, 31 (1), 91-113.

Chul, Han-Byung (2012): La sociedad del cansancio. Editorial: Herder.

Clough, Patricia, Halley, Jean (eds.) (2007): The Affective Turn: Theorizing the Social. New York: Duke University Press Books.

Crary, Jonathan (2015): 24/7: Capitalismo tardio y el fin del sueño. Madrid: Ariel.

Dalla Costa, Maria Rosa (2009): Dinero, perlas y flores en la reproducción feminista. Madrid: Akal.

Daly, Mary, Lewis, Jane (2000): «El concepto de Social Care y el análisis de los Estados de Bienestar» en Cristina Carrasco, Cristina Borderías y Teresa Torns (eds.) El Trabajo de Cuidados. Historia, teoría y politicas, Madrid: Catarata, 223-250.

Diaz-foncea, Millán, Marcuello, Carmen, Monreal, Manuel (2015): «Economía social y economía colaborativa: Encaje y potencialidades", Economía Industrial, n. ${ }^{\circ} 402,27-35$.

Donath, Orna (2016): Madres arrepentidas: una mirada radical a la maternidad y sus falacias sociales. New York: Penguin Random House.

Ehrenreich, Barbara (2009): Sonrie o muere: la trampa del pensamiento positivo. Madrid: Turner NOEMA.

Espluga, Eudald, Gómez, Berta Gómez, Santo, Tomás (2018): «Del feminismo al infierno: cómo el capitalismo puso la ética del cuidado al servicio del mercado», El Salto edición Digital, Extraído el 2018/05/30 de https://www.elsaltodiario.com/laplaza/delfeminismo-al-infierno-como-el-capitalismo-puso-la-etica-del-cuidado-al-servicio-delmercado-

Ezquerra, Sandra (2012): «Acumulación por desposesión, género y crisis en el Estado Español», Revista de Economía Crítica, n. ${ }^{\circ} 14$, pp: 124-147.

Federici, Silvia (2018): El patriarcado del salario. Criticas feministas al marxismo. Madrid: Traficantes de Sueños.

- (2010): Calibán y la bruja. Madrid: Traficantes de Sueños.

Florida, Richard (2010). La clase creativa. La transformación de la cultura del trabajo y el ocio en el Siglo XXI. Madrid: Paidós.

GiL, Javier (2016): «Ciberpolítica: Gobierno abierto, redes, deliberación, democracia, Un análisis a través de la prosumición», por Ramón CoRTARelo García, Javier GIL (comp.), 167-188

Gold, Michael and Mustafa, Mona (2013): 'Work always wins': client colonisation, time management and the anxieties of connected freelancers», from New Technology, Work and Employment N. $28: 3$. pp: 197-211.

Harney, Stefano, Moten, Fred (2013): Los abajocomunes. Planear fugitivo y estudio negro. Edición Online: https://transversal.at/books/los-abajocomunes

HarTsock, Nancy (2011): «A New Moment of Primitive Accumulation» en Inkrit Conference.

Harvey, David (2003): The new Imperialism. Nueva York: Oxford University Press.

Herrero, Yayo (2013): "Miradas ecofeministas para transitar a un mundo justo y sostenible», Revista de Economia Crítica, n. ${ }^{\circ} 16,278-306$.

Himmelweit, Susan (1995): "The Discorvery of «Unfaid Work»: The Social Consecuences of the Expansion of "Work», Feminist Economics, 1 (2), 1-19.

Hochschild, Arlie R. (1983). The managed heart: Commercialization of human feeling. Berkeley: University of California Press. 
- (1995): «The Culture of Politics: Traditional, Postmodern, Cold-modern, and Warmmodern Ideals of Care», Social Politics: International Studies in Gender, State \& Society, Vol. 331-346.

-(200I): «Las cadenas mundiales de afecto y asistencia y plusvalía emocional» EN Hutton, Will, Giddens, Anthony (coord.) En el limite, Barcelona: Tusquets, 187208.

-(2008): La mercantilización de la vida intima. Apuntes de la casa y el trabajo. Argentina: Akal.

Illouz, Eva (2011): La salvación del alma moderna. Terapia, emociones y la cultura de la autoayuda. Madrid: Katz.

IzQUIERDo, Maria Jesús (2003): «Del sexismo y la mercantilización del cuidado a su socialización: Hacia una política democrática del cuidado», Cuidar Cuesta: costes y beneficios del cuidado, Bilbao: Sare.

Landa, Inés, Marengo, Leonardo (2010): «Devenir cuerpo empresa. El nuevo capitalismo y sus tramas de sujeción", Actuel Marx / Intervenciones, vol 9.

López, Pablo (2016): «La plasticidad forzada. Cuerpo y trabajo», Daimon. Revista Internacional de Filosofia, Suplemento 5, 679-688

Macías, Alfredo (2017): El colapso del capitalismo tecnológico. Editorial: Escolar \& Mayo.

Marx, Karl (1867) (2008): El Capital. Crítica de la Economía Política. Nueva York: Editors

Massumi, Brian (2002): Parables for the Virtual: Movement, Affect, Sensation. Durham, NC: Duke University Press Books.

Mogollón, Irati, Legarreta, Matxalen (2015): «Estrategias colectivas para la sostenibilidad de la vida en tiempos de crisis. El caso de Calafou», Encrucijadas, Revista Critica de Ciencias Sociales, n. ${ }^{\circ 9}, 1-21$.

Morini, Cristina (2017): Por amor o a la fuerza: Feminización del trabajo y biopolitica del cuerpo. Madrid: Traficantes de Sueños.

Ortega, A. Santos (2018): «La revolución emprendedora como política de activación y creación de nuevas subjetividades entre los jóvenes", Ciencias Laborales y emprendimiento. Valencia; Neopatria.

Ostrom, Elinor (1990): Governing the commons: The evolution of institutions for collective action. Political economy of institution and decision. Indiana University: Cambridge University Press.

Отто. C (20 I 8): «La gran mentira de la nueva economía: prometieron innovación y trajeron miseria» extraido de El Confidencial el 23/07/2018 de https://blogs.elconfidencial.com/tecnologia/emprendedorfurioso/2018-07-23/mentira-economia-colaborativa-precariedad-uber-airbnb-deliveroo-glovo_1575843/

Perez-Orozco, Amaia (2006): Perspectivas feministas en torno a la economía: el caso de los cuidados. Madrid: Consejo Económico y Social.

-(20I4): Subversión feminista de la economía. Aportes para un debate sobre el conflicto capital-vida. Madrid: Traficantes de Sueños.

Picchio, Antonella (1992): «El trabajo de reproducción, tema central en el análisis del mercado laboral», en Cristina Carrasco, Cristina Borderías y Teresa Torns (eds.) Las mujeres y el trabajo. Rupturas conceptuales. Barcelona: Icaria.

—(2009): «Condiciones de vida: perspectivas, análisis económico y políticas públicas» en Revista de Economía Crítica, 7, pp: 27-54.

Pine, Joseph, Gilmore, James (1991): The Experience Economy. Massachusetts: Harvard Bussines Review Press. 
Piñeiro, Concepción, Suriñach Rubén, Fernández, Jose Luis (2017): «Entre el mercado y la cooperación social. Luces y sombras de las prácticas de consumo colaborativo", Revista Española de Sociología, 26 (1), 97-108.

Solanilla, Paul (2018): «Del capitalismo financiero al capitalismo tecnológico», en Nuevatribuna, extraido el 21/11/2018, en https://www.nuevatribuna.es/articulo/econo$\mathrm{mia} /$ capitalismo-financiero-capitalismo-tecnologico/20180911103538155545.html

SQuire, Corinne (2001): "The public life of emotions», International Journal of Critical Psychology, 1, 27-38.

STIGLiTZ, Joseph (2002): El malestar en la globalización. Madrid: Taurus.

Taylor-Gooby, Peter (ed.) (2004): New Risks, New Welfare: The Transformation of the European Welfare State, Oxford University Press.

Thomas, Carole (1993): «Deconstruyendo los conceptos de cuidado», en Cristina Carrasco, Cristina Borderías y Teresa Torns (eds.) El trabajo de cuidados. Historia, teoría y politicas, 143-174. Madrid: Fuhem ecosocial y Catarata.

Valenzuela, Hugo, Reygadas Luis, Cruces, Francisco (2015): «Mi trabajo es mi vida. La incrustación de los mundos de la vida y del trabajo en empresas españolas», Reis Revista Española de Investigaciones Sociológicas, 150, 191-210. 